\title{
Jonathan Ovesen
}

\section{Nazistisk ukrudt i retorikkens have - Victor Klemperers metodiske tilgang i LTI som retorisk redskab}

Tidsskriftet Sakprosa

Bind 9, Nummer 2

(C) 2017 


\section{Sammendrag}

Nazismen og retorikfaget står på mange måder i et prekært forhold til hinanden. Der er ikke skrevet meget om nazismens retorik på et retorisk grundlag. Men et værk, der for den retoriske forskning måske er værd at dykke ned $i$, er Victor Klemperers Lingua Tertii imperii fra 1947. Jeg vil $i$ denne artikel undersøge værkets metodiske og teoretiske tilgang til nazismens retorik for at se, om værket har noget at tilbyde den moderne retorikforskning og vice versa. I artiklen undersøger jeg, hvordan Klemperers værk kan opfattes som et teoretisk og metodisk foregangsværk for den moderne retorikforskning, samt hvordan værket baner vej for fremtidige retoriske undersøgelser af nazismens retorik. Artiklen udfolder desuden en kritisk diskussion af Klemperers publikumsforståelse og peger på vigtigheden af den moderne retoriks forståelse affolket eller massen som en retorisk konstruktion. Afslutningsvis diskuterer jeg, hvorfor det er vigtigt for retorikforskningen at belyse og forstå nazismens retorik - en retorik, der vinder frem $i$ vores tid, og som derfor er en opgave for retorikfaget at begribe.

\section{Abstract}

In many ways, the relationship between rhetoric and Nazism could be described as precarious. However, the literature concerning Nazi rhetoric on a rhetorical ground is often considered to be insufficient, if not to say poor. Victor Klemperer's Lingua Tertii imperii, from 1947, makes an interesting exception to this. Positing that Klemperer's work can be perceived as a pioneering work in this field, I intend to investigate his methodological and theoretical approaches. Through a critical discussion about Klemperer's understanding of audience, I explore how the work carves the path for future rhetorical studies of Nazi rhetorics, pointing to the importance of the modern rhetorical understanding of the people, or the mass, as a rhetorical 
construction. Finally, I discuss why it is important for the field of rhetoric to shed light on and to understand Nazi rhetoric - a rhetoric of renewed prominence in our time.

\section{Om forfatteren:}

Jonathan Ovesen arbeider med en masteravhandling om nazismens retorikk ved Københavns Universitet. 


\section{Nazistisk ukrudt i retorikkens have - Viktor Klemperers metodiske tilgang i LTI som retorisk redskab}

Hitler og nazismen står måske for en af verdens største og mest grusomme demonstreringer af, hvordan sprog kan bruges som afgørende faktor i ændringen af et samfunds mentalitet, adfærd og moral. Nazismens sproglige magt påvirkede ikke bare en mindre gruppe, men millioner af mennesker på tværs af samfundsklasser i Tyskland. En demonstrering af sproglig påvirkningskraft, der ikke har sit lige noget sted i menneskets historie - og som uden tvivl har gjort sprogets magt til noget mistænksomt og farligt lige siden.

Retorikfaget beskæftiger sig med det overbevisende og effektive sprog, men er samtidig konstitueret af etikken og en stræben efter det gode deliberative demokrati. Det er en forståelse af retorik som en "sidegren af dialektikken og af etikken, som rettelig må betegnes som hørende under statslæren (politike)”, som Aristoteles (2007) skriver i sin Retorik. (s. 35) Denne inkorporering af etikken i retorikfaget videreføres af senantikke tænkere som Cicero og Quintilian og deres forestilling om taleren som orator perfectus - vir bonus dicendi peritus (den gode mand, der taler godt). Den gode retorik er ikke bare effektiv, den er også etisk. En dualitet, der kan siges at være totalt opløst og fraværende under nazismen.

Dualiteten mellem det effektive og det etiske fik Perelman og Olbrechts-Tyteca til at distingvere mellem retorik og propaganda i værket The New Rhetoric: $A$ Treatise on Argumention (1958/1971). Som Hanne Roer (2005) skriver i forordet til Retorikkens Rige (den danske oversættelse og forkortede udgave af The New Rhetoric): "Den nye argumentationsteori skal i aristotelisk ånd 
kunne bruges til at afgrænse retorik fra manipulation og propaganda - det 20. århundredes frygtindgydende svar på sofismen.” (s. 11)

Hitlers udnyttelse af sprogets magt blev altså en igangsætter af en ny bølge af retorisk tænkning, der forsøgte at give modsvar og pege på læren om retorik som en vigtig ressource til at forhindre totalitære regimer. Det blev starten på retorikfagets genopblomstring og en ny æra i fagets historie. Som David A. Frank skriver i bogen The Effects of Rhetoric and the Rhetoric of Effects (2015):

\footnotetext{
Rhetoric was used as an instrument to promote and carry out genocide. Indeed, the origins of twentieth-century rhetorical theory in the United States and Europe and the exigence for a thorough account of rhetoric's effects can be traced to Kenneth Burke's confrontation with Mein Kampf, Chaim Perelman's reflection on Holocaust, and Hannah Arendt's postWorld War II writings on totalitarianism. [...] Their focus on the freedom afforded by rhetoric is a function of their rhetorical situation; they were confronting Hitler and totalitiarian thought. (s. 102-103)
}

Men som Amos Kiewe og Davis W. Houck (2015) også redegør for i samme bog, er fokus på retorisk effekt ikke en stabilt forekommende tilgang i det moderne retorikfags historie: "It was hailed as the key focus of rhetorical criticism but later dismissed, its scope narrowed then elevated, later impugned and then recently resurrected be several prominent scholars.” (s. 1)

Forskningslitteratur om nazismens tilblivelse, betydning og påvirkning er enormt omfangsrig og udspringer af mange forskellige akademiske fagområder. Det er i kontrast hertil bemærkelsesværdigt, at den moderne retorikforskning kun i et meget lille omfang har bidraget til denne forskningslitteratur. En række artikler og værker skal dog i denne forbindelse nævnes. I Quarterly Journal of Speech er der skrevet en række artikler om Hitlers retorik, herunder bl.a.: 
"Mythic Rhetorician in Mein Kampf: A Structuralist Critique" (1977) af Michael McGuire, “The Self-Taught Agitator: Hitler. 1907-1920” (2009) af Richard W. Wilkie, “The Nazi Rhetorician” (2009) af Ross Scanlan og "In Search of “The People': A Rhetorical Alternative” (1975) af Michael C. McGee.

I Communication Quarterly har Jeffrey W. Murray skrevet artiklen "Constructing the ordinary: The dialectical development af Nazi ideology" (1998).

I Symbolic Interaction har Michael Blain skrevet artiklen "Fighting Words: What we can learn from Hitler's hyperbole" (1988).

I Rhetorica Scandinavica har Birgitte Mral skrevet artiklen “Demagogens röst. Hitler som radiotalare" (2010).

Og så har Søren Gosvig Olesen, lektor I filosofi på Københavns Universitet, skrevet en vigtig og omfattende bog om Hitlers retorik og retoriske tænkning med titlen: Hitler. En introduktion (2010).

Hermed ikke sagt, at der ikke kan fremdrages andre eksempler end disse relativt få på retoriske analyser af nazismens og Hitlers retorik. Men taget den historiske begivenheds retoriske relevans og omfattende betydning $\mathrm{i}$ betragtning, kan det virke påfaldende, at man ikke snarere drukner i analyser og retoriske kritikker.

\section{Victor Klemperers LTI}

Nazismens retoriske effekter på den tyske befolkning er til gengæld undersøgt af filologen Victor Klemperer, der skrev i tiden før og under krigen. Han står for den mest gennemførte og omfattende empiriske analyse af det nazistiske sprogs påvirkning. Og måske kan hans værk, LTI, tilbyde retorikforskningen nogle metodiske tilgange og perspektiver, der kan åbne op for en beskæftigelse med nazismens retorik. Mens nazismen blev anstød til en ny retorisk tænkning på et teoretisk plan, er det bemærkelsesværdigt, hvor få retoriske analyser af nazismens retorik, der er lavet efter Burkes artikel "The Rhetoric 
of Hitler's 'Battle"” (1939). Klemperers værk er interessant i en retorisk kontekst, idet værket er et eksempel på en analyse af nazismens retorik og retoriske effekt.

I 1947 udkom Klemperers bog LTI - Lingua Tertii imperii. Det Tredje Riges Sprog - En filologs notesbog (1947/2010). Klemperer var tysk professor i romansk filologi, men grundet hans baggrund som jøde, fik han af nazisterne frataget sit professorat i 1934. Bogen bygger på Klemperers 4000 siders lange dagbog fra årene 1933 til 1945, hvor han gennem 12 år observerede samfundet under nazismen. Bogen er et koncentrat fra dagbogen af de observationer, der vedrører nazismens særegne sprog og dens effekt på befolkningen. Og selvom Klemperer skriver i en tid, hvor retorik ikke regnes for meget andet end manipulation og folkelig forførelse, som han selv skriver: "retoren - som går tilbage til den græske sofisme og dens forfaldstid - er frasemageren, den som omtåger forstanden” (Klemperer, 2010, s. 69), så gør han sig mange analytiske iagttagelser, der samstemmer med retorisk teori og sproglig grundopfattelse.

\section{Artiklens undersøgelse af Klemperers $\mathbf{L} T$}

Artiklen er en retorisk undersøgelse af Klemperers værk, LTI, med særligt fokus på Klemperers metodiske og teoretiske tilgang. Værket er retorisk interessant, fordi Klemperer bruger observation over en længere årrække som metode for sit studie frem for at fokusere på nærlæsning af en enkeltstående tekst. Indenfor den retoriske forskning er tendensen til at åbne op for sådanne metoder og tilgange stigende. Og jeg mener, at retorisk forskning både kan lære noget af Klemperers metodiske tilgang og hans akademiske behandling af en historisk begivenhed, der i en retorikvidenskabelig sammenhæng kan have mange interessekonflikter og kontradiktioner.

Værket er tidligere blevet kritiseret for at mangle en teoretisk konsistens: 
Et gennemgående træk i kritikken fra den mere puritanske lingvistik i 1970'erne og 1980'erne har været, at LTI manglede en konsistent sprogteori. Set i nutidens teoretiske perspektiv er det den kritik, der er forældet. Victor Klemperers analyser af enkeltord, metaforik, symboler, genstande og handlinger er hele tiden kontekstrettet og social/historisk funderet. (Vangsgaard, 2010, s. 393)

Dette er en fundering, som også retorikfaget bygger på. Jeg vil i artiklen undersøge, om Klemperers værk kan opfattes som et tidligt retorisk studie, der ud over det metodiske plan, også på det teoretiske område arbejder med betragtninger og tilgange, retorikforskningen først er begyndt at anvende i nyere tid.

For det første undersøger jeg, hvordan Klemperer foregriber en moderne erkendelse af, at retoriske ytringer og påvirkninger er fragmenterede, fordi de kommer til udtryk i en fragmenteret virkelighed. Her inddrager jeg dels Calvin McGees artikel "Text, Context, and the Fragmentation of Contemporary Culture" (1990) og dels Jens E. Kjeldsen artikel "Retorikken i en fragmenteret, foranderlig og kompleks verden” (2008).

For det andet undersøger jeg, hvordan Klemperers værk foregriber studierne om den vernakulære retorik fra 1990’erne. For at belyse dette, inddrager jeg to teorier om vernakulær retorik, dels Kent A. Ono \& John M. Sloops “The Critique of Vernacular Discourse” (1995) og dels Gerard A. Hausers Vernacular Voices (1999).

Men jeg mener også, at den moderne retorikforskning kan bidrage med en teoretisk fundering til Klemperers værk, der måske kan belyse nogle af Klemperers observationer og klargøre deres retoriske relevans. Artiklen udfolder en kritisk diskussion af Klemperers publikumsforståelse med inddragelse af den spanske filosof og kulturteoretiker José Ortega y Gassets 
Massernes oprør (1929/1964) og Michael C. McGees artikel "In Search of 'The People': A Rhetorical Alternative” (1975).

Afslutningsvis forsøger jeg at pege på, hvordan og hvorfor retorikforskningen, særligt i lyset af den nutidige reetablerede interesse for retorisk effekt, ${ }^{1}$ bør beskæftige sig med nazismen.

Artiklen vil undersøge, hvordan Klemperers værk tilbyder sig som et eksempelstudie i nazismens retorik, der kan bruges som afsæt til videre forskning. Der er stadig rigtig mange ubesvarede spørgsmål i forhold til nazismens retoriske påvirkningskraft, som retorikforskningen kan være med til at belyse. Som Klemperer (2010) selv skriver:

Det bliver nemlig nødvendigt at udføre et stort specialistarbejde på mange forskellige områder, [specialister red.] skal løse mange enkeltproblemer i ekskurser og hele doktorarbejder, før et modigt og klogt hoved tør fremstille Lingua Tertii Imperii i sin helhed, i al dets tarvelige og righoldige helhed. Men en første famlen og spørgen [...] vil imidlertid altid have værdi for en senere tids forsker. (s. 27)

${ }^{1}$ Amos Kiewe og David W. Houck gennemgår i introduktionskapitlet til bogen The Effects of Rhetoric and the Rhetoric of Effects. Past, Present, Future (2015) den moderne retorikforsknings skiftende fokus på retorisk effekt op gennem det 20. årh. og starten af det 21. årh. Gennemgangen starter ved Herbert Wichelns værk The Literary Criticism of Oratory (1925) og bevæger sig derfra op til en længere række af retorikere fra starten af det 21. årh., hvor man igen begynder at beskæftige sig med retorisk effekt. 


\section{Klemperers overordnede antagelse}

Klemperer undersøger Det tredje riges sprogs påvirkning af befolkningen ud fra en hovedtese, der formuleres således:

[D]en stærkeste påvirkning blev ikke udøvet af de enkelte taler, heller ikke af artikler eller af flyveblade, plakater eller faner, den blev ikke opnået af noget, man var nødt til at indoptage med bevidst tænkning eller bevidste følelser.

Nazismen gled tværtimod over i massernes kød og blod gennem enkelte ord, faste udtryk og sætningsformer, som de fik påtvunget gennem millioner af gentagelser, og som blev overtaget mekanisk og ubevidst. (Klemperer, 2010, s. 28)

Ved at observere befolkningens sprog, både hos jøder og ikke-jøder, forsøger Klemperer at dokumentere, hvordan nazisternes retorik blev overtaget og brugt af befolkningen i stigende grad gennem 12 år. Klemperer holder et særligt fokus på to ting: For det første undersøger han enkelte ord, udtryk og sætningsformer og for det andet undersøger han, hvordan nazismens retorik indlejres og anvendes i befolkningens hverdagssprog.

\section{Klemperers filologiske opmærksomhed: Det enkelte ord}

Klemperer fokuserer bevidst på enkelte ord og vendinger og altså ikke på retoriske ytringer i deres helhed: "For det enkelte ord afslører en epokes tænkning, den almene tænkning, som individets tanker er indlejret i, påvirket af, måske styret af.” (ibid, s. 175)

Det har den fordel, at Klemperer på den måde får et retorisk fokus at observere ud fra, fremfor at skulle observere retoriske ytringer i deres helheder, som fx hele samtaler eller hele radioudsendelser. I stedet fokuserer 
han på, at opfange enkelte ord og vendinger, han kan dokumentere struktureret.

Hans undersøgelse viser, at nazisterne brugte en lang række ord og vendinger på nogle nye måder, man ikke havde hørt tidligere, og som blev overtaget af befolkningen i hverdagssproget. Klemperer leder ikke nødvendigvis efter nye ord, men ord der bruges på nye måder, med nye betydninger og i nye kontekster. Fx belyser han ordet fanatisk:

Hvis en person siger fanatisk (fanatisch) i stedet for heltemodig (heldisch) og dydig (tugendhaft), tror han til sidst virkelig, at en fanatiker er en dydig helt, og at man ikke kan være en helt uden at være fanatisk. Det Tredje Rige opfandt ikke ordene fanatisk og fanatisme, det ændrede kun deres værdi og brugte dem mere i løbet af en dag, end andre epoker gennem flere år. (ibid, s. 29)

Da Klemperer har sit videnskabelige udgangspunkt i filologien, fortolker han sine observationer ud fra en filologisk tilgang, der fokuserer på ordenes oprindelse og oprindelige betydning:

Fanatique og fanatisme er ord, som de franske oplysningsforfattere anvender i en meget dadlende betydning [...]. Oprindeligt - ordet har sin rod i fanum, helligdom, tempel - er fanatikeren et menneske, der befinder sig i en tilstand af religiøs henrykkelse, ekstatisk krampe. [...] Hvor oplysningstidens tankegods end viser sig, er det alle steder forbundet med en følelse af modvilje og misbilligelse mod begrebet fanatisme (ibid, s. 7475).

Det er denne misbilligelse, nazisterne vender om i deres positive brug af ordet fanatisk. Og det har en konsekvens for befolkningens måde at opfatte verden på, idet fanatiske handlinger legitimeres - ja, endda ophøjes som en menneskelig dyd. Som Klemperer udtrykker det i en giftmetafor: "Ord kan virke som bittesmå doser arsenik: De sluges ubemærket, de synes ikke at have 
nogen virkning, men efter noget tid viser giftens virkning sig alligevel.” (ibid, S. 29)

Den retoriske påvirkningskraft ligger ifl. Klemperer ikke i nazisternes måde at anvende ordene i nye betydninger. Påvirkningskraften ligger ikke i nazisternes retorik, men i dens møde med befolkningens sprogbrug:

\footnotetext{
Men frem for alt, og det er den mening, jeg principielt følger i alle vigtige refleksioner, at for mig drejer det sig ikke om at konstatere, hvornår et udtryk eller en vending dukker op første gang, for det er i de fleste tilfælde umuligt [...]. For et ord eller den særlige farvning og vurdering af et ord får først liv inden for et sprog, når de indgår i en gruppes eller i almenhedens sprogbrug og er i stand til at sætte sig igennem i en vis tid. (ibid, s. 64)
}

Klemperer belyser, hvordan enkelte ord og vendinger kan udøve magt over modtagerne og sætte dem i stand til at handle i overensstemmelse med den nazistiske agenda:

det (nazistiske sprog red.) ændrer ordenes værdi og anvendelseshyppighed, [...] det gør sproget til tjener for sit frygtelige system, og i sproget får det sit mest magtfulde, mest offentlige og mest uhyggelige reklamemiddel. (Klemperer, 2010, s. 29)

\section{Retorikkens og virkelighedens fragmentering: Et retorisk grundvilkår}

Flere forskere peger på, at retorikforskningen står overfor en ny udfordring, idet virkeligheden er mere fragmenteret end tidligere. Retorik udøves ikke bare i en tale holdt af en taler til et afgrænset publikum, men i mange forskellige situationer med forskellige afsendere og modtagere. Derfor er man nødt til at konstruere den "tekst", man vil analysere. 
To forskere, der har peget på denne realitet som et særligt træk ved den moderne verden, er Michael Calvin McGee i artiklen "Text, Context, and the Fragmentation of Contemporary Culture" (1990) og Jens E. Kjeldsen i artiklen "Retorikken i en fragmenteret, foranderlig og kompleks verden" (2008).

McGee (1990) skriver:

Critical rhetoric does not begin with a finished text in need of interpretation; rather, texts are understood to be larger than the apparently finished discourse that present itself as transparent. [...] In the not-too-distant past, all discourses were what social theorist call 'totalizations' [...].That is, all structures of a text were homogeneous. [...] A central requirement of our new circumstances is simply finding a place to start thinking about it. (s. 279-284-286)

Kjeldsen (2015) lægger særlig vægt på samtidens pluraliserede medievirkelighed og de nye mediers betydning for retorisk forskning:

Empiriske receptionsorienterede studier er særlig velegnet i vor tids fragmentariske, multimedierede samfund. [...] I vor tid er hverken publikum eller retoriske ytringer klart afgrænsede som enkeltstående enheder. Det er en af de største udfordringer for retorisk analyse i vor tid. (s. 273)

Denne medievirkelighed er markant anderledes end virkeligheden i 1930'ernes Tyskland. Men jeg mener alligevel, at Klemperers værk i denne henseende trækker tråde op til den nutidige retoriske forskning. For måske peger Klemperers analyse på, at diskurs og retorisk påvirkning allerede i starten af det 20 årh. skulle findes i en fragmenteret og kompleks virkelighed - eller måske endda, at det er et grundlæggende karakteristika ved retoriske ytringer og påvirkninger. Den fragmentering, som Kjeldsen forstår som et moderne fænomen med rod i 2000-tallets mediesituation, peger Klemperers studie snarere på som et modernitetsfænomen - eller måske endda et træk 
ved retorisk påvirkning, der går på tværs gennem menneskesamfundets historie.

Det er rigtigt af Kjeldsen at påpege, at der i retorikforskningen historisk har været et overvejende, næsten udelukkende, fokus på enkeltstående taler og tekster. Et fokus, som nu i højere grad er opløst, og hvor den moderne mediesituation tænkeligt har haft en stor betydning for erkendelsen af den retoriske fragmentering. Men det betyder ikke, at den retoriske påvirkningskraft altid har ligget i den enkelte tale og først nu er fragmenteret. Selv i en virkelighed uden moderne medier, kan Klemperer pege på, at påvirkningskraften skal findes i en fragmenteret retorisk proces.

Kjeldsen (2008) kommer med tre veje, han mener den nutidige retorikforskning bør gå: "Kortlægge den flydende og foranderlige retoriske situationalitet" (s. 51), der handler om at belyse samfundsmæssige, politiske, historiske og kulturelle kontekstuelle omstændigheder. Herudover bør den “[u]ndersøge retorisk reception og rejse” (s. 55), der handler om empirisk at undersøge retoriske ytringers effekt og fortolkning hos modtagerne gennem andre metoder end tekstlæsning. Og til sidst bør den “åbne for en mere samfundsvidenskabelig og sociologisk orienteret forskning”. (s. 57)

Det er disse tre tilgange til den retoriske undersøgelse, vi ser demonstreret af Klemperer allerede i 1947. Han undersøger for det første magthavernes fragmenterede retorik, der ikke bare består af isolerede taler eller artikler, men i en stor variation af ytringer og symboler i mange forskellige kontekster. Og for det andet undersøger han den fragmenterede retorik, der igangsættes hos befolkningen. Det gør han ved observation over en længere årrække som metode understøttet af særligt historiske og kulturelle refleksioner.

Klemperer bliver gennem sit studies 12 års varighed mere og mere begrænset i hans tilgang til aviser, bøger og lignende. Så i stedet for at studere mere 
isolerede, enkeltstående tekster, begynder han, hvor han har mulighed for det, at observere den fragmenterede retorik, der kommer til udtryk hos nazisterne og den tyske befolkning:

\footnotetext{
Jeg iagttog stadig nøjere, hvordan arbejderne talte på fabrikken, og hvordan udyrene i Gestapo talte, og hvordan vi jøder selv udtrykte os, i jødeburenes zoologiske have. Man kunne ikke mærke nogen forskel, nej slet ingen. Alle, tilhængere og modstandere, udnyttere og ofre, var styret af de samme mønstre. [...] Men det som havde været en barneleg for tusinde andre mennesker, nemlig at undersøge disse mønstre, var utrolig vanskeligt, altid farligt og ofte aldeles umuligt for mig. (Klemperer, 2010, s. 25)
}

Det er Klemperers begrænsede tilgang til et undersøgelsesmateriale, der tvinger ham til at konstruere analyseteksten selv ud fra det sprog, som møder ham i hverdagen. En konstrueren, der løbende ledsages af en refleksion over, hvad der bør medregnes i det tredje riges sprog. Fx en overvejelse om, hvorvidt det gule jødekort på tøjet bør medregnes: “Atter spørgsmålet om afgrænsning: hører det til Det Tredje Riges sprog?” (ibid, s. 51)

Idet han fratages sin stilling på universitetet, hvor han ikke længere kan forske i det 18 århundredes franske litteraturhistorie, drages han til at vende blikket mod sin egen tids sprog: "derfor blev Det Tredje Riges sprog det, jeg i bogstavelig og konkret filologisk forstand klamrede mig til, og det blev min balancestang hen over tomgangen”. (ibid, s. 23) Og fordi han blev fastlåst og begrænset $\mathrm{i}$ al den tid nazisterne havde magten, strakte hans studie sig over 12 år. Dette tidsperspektiv giver mulighed for at kunne undersøge en udvikling $\mathrm{i}$ retoriske ytringers gradvise virkning på befolkningen. Et sådan indblik i retoriske ytringers virkningsudvikling ville ikke være mulig hverken ud fra isolerede tekstlæsninger eller andre metodiske tilgange med kort tidshorisont.

Klemperers erkendelse af, at den retoriske påvirkningskraft ikke bare skal findes i afgrænsede tekster, men i en fragmenteret retorisk virkelighed, gør, at 
hans værk på dette punkt er forud for den moderne retoriske forskning, der efter Klemperers værk primært beskæftigede sig med nærlæsning af enkelte taler. Hvis man vil begribe den retorik, der udøves i et samfund, må man samtidig erkende, at den udøves i en fragmenteret virkelighed.

\section{Den vernakulae retorik}

Gennem langvarig observation forsøgte Klemperer at dokumentere, hvordan nazisternes retorik blev et spejl for befolkningens sprog. Hans observationer giver en karakteristik af befolkningens sprog som en gradvis kopiering af det tredje riges sprog, "som blev overtaget mekanisk og ubevidst." (ibid, s. 28) Der dokumenteres altså ingen tegn på modretorik hos befolkningen. Modtagerne af det tredje riges sprog karakteriseres som en passiv masse, der blot ekkoer den retorik, som tales til dem.

At undersøge den retorik, der foregår i befolkningen, frem for at undersøge magthavernes og institutionernes retorik, er beskrevet i teorierne om den vernakulære retorik. Klemperer undersøger først og fremmest befolkningens retorik. Hans værk kan betragtes som en tidlig undersøgelse af vernakulær retorik, inden denne teoretiske retning blev introduceret $\mathrm{i}$ kommunikationsforskningen i midten af 1990'erne. Men hans observationer peger på nogle forhold, som ikke helt er i overensstemmelse med flere af de moderne teoretiske antagelser om den vernakulære retorik.

Som Robert Glenn Howard skriver i bogen Public Modalities - Rhetoric, Culture, Media, and the Shape of Public Life (2010), findes der "two primary theories of the vernacular in communication research". (s. 242) Den ene er Ono og Sloops The Critique of The Vernacular Discourse (1995), den anden er Hausers Vernacular Vioces (1999). De har det tilfælles, at de begge definerer den vernakulære retorik som ikke-institutionel. Men mens Ono og Sloop går ud fra "a distinction between vernacular and institutional agents", går Hauser 
ud fra "a distinction between vernacular and institutional agencies." (Howard, 2010, s. 242) Forskellen består i, at "Hauser refers to a diffuse set of communication practices generally available, [...] Ono and Sloop imagine the vernacular in reference to historically disempowered groups.” (ibid, s. 243)

\section{Ono \& Sloop: Retorikken i undertrykte grupper}

Klemperers tilgang til det vernakulære er høj grad i overensstemmelse med Ono og Sloops teori. De argumenterer for, at retorikere bør undersøge den retorik, der foregår i "communities that have been systematically ignored" (Ono \& Sloop, 1995, s. 20). For at eksemplificere det, peger de netop på Burkes analyse af Hitlers Mein Kampf overfor retorikken i den jødiske befolkning: "Burke made the choice to analyze Hitler's rhetoric rather than the rhetoric of Jews in Warsaw and Berlin. He made the choice to criticize the man in control, not those buckling under his fist." (ibid, s. 19)

Og det er præcis den analyse, som Ono og Sloop efterspørger, Klemperer har lavet. Men han begrænser sig ikke til jødernes retorik, han inkluderer hele befolkningen i sine observationer. Den tyske befolkning som helhed, både jøder og ikke-jøder, kan i Klemperers historiske kontekst opfattes som en politisk undertrykt gruppe. En udvidelse som Ono og Sloop (1995) heller ikke er helt afvisende overfor: "This is not to say that localized communities, generally, should not be studied". (s. 20)

Men mens Klemperer undersøger den retorik, der foregår iblandt befolkningen, altså en mange-til-mange-kommunikation, undersøger Ono og Sloop (1995) en vernakulær retorik, som er målrettet til undertrykte grupper, altså snarere en en-til-mange-kommunikation: "Rather, we examine discourse within the Pacific Citizen to show how the newspaper constructs itself as a vernacular medium through which information about Japanese Americans is articulated." (s. 28) 
Som jeg belyser i næste afsnit, har Klemperer på dette punkt mere tilfælles med Hausers vernakulære retorik.

Ono og Sloop (1995) beskriver to forskellige "characteristics of vernacular discourse" (s. 21). Den ene, Cultural syncretism, er en vernakulær retorik, der fungerer som en mod-retorik overfor den dominerende kultur, mens den anden, Pastiche, fungerer som fragmenterede efterligninger af populærkulturen. Klemperers karakteristik af den tyske befolknings retorik implicerer den sidste af de to aspekter. Men for Ono og Sloop (1995) er dette aspekt en positiv styrke ved det vernakulære: "Vernacular discourse can combine elements of popular culture in such way as to create a unique form that implicitly and often explicitly challenges mainstream discourse." (s. 23). Klemperer peger på, at der netop ikke etableres en sådan udfordring af mainstream-diskursen - altså det tredje riges sprog.

Som Howard (2010) skriver om Ono og Sloop: "Their most enduring point may be that the vernacular is open to critique at least because it sometimes acts to support hegemonic power structures." (s. 244) Det er, for Ono og Sloop, denne mere undtagelsesmæssige funktion ved det vernakulære, som Klemperer peger på som et helt gennemgående træk i den tyske befolknings retorik under krigen.

\section{Hauser: Offentlig meningsdannelse og retorisk handlekraft}

To ting Klemperer har tilfælles med Hausers vernakulære retorik, er dels hans empiriske fokus på diskursen som den udfolder sig i befolkningen og dels hans brede tekstopfattelse. Som Hauser (1999) skriver:

I propose that an empirical disposition toward the dialogue of informal discourse, or a vernacular rhetoric model, provides a deeper understanding of public opinion [...]. Taking actual discourse as the prima facie evidence from which we infer public opinion elevates the ongoing 
concerns of social actors to a central place in detecting and deciphering its content. (s. 83)

Hvis man skal analysere den retorik, der kommer til udtryk i befolkningen, har man ikke en enkeltstående tekst at gå til. Derfor er man nødt til selv at konstruere sin analysetekst, hvilket forudsætter en stillingtagen til, hvad der skal regnes for en del af denne tekst. Både Klemperer og Hauser har en bred tekstopfattelse, hvor de inkluderer næsten alle former for kommunikative og symbolske handlinger. Hauser (1999), der observerer det græske valg i 1985 , registrerer alle indtryk fra gadebilledet:

I could see men leaning out their windows, waving identical banners of the favored party, and shouting slogans to pedestrain traffic [...]. Moreover, each was a communicative act that entered into a national discourse on policy and direction, as occurs during national elections. (s. 86-89)

På samme måde har Klemperer et bredt tekstbegreb, hvor han registrerer alt omkring sig fra gadeoptog til radioudsendelser, avisartikler, varedeklarationer, bøger, taler, snakken hos købmanden, på arbejdspladserne og blandt vennerne. Fx opdager han ordet militærsport på universitetet, hvor de studerende fik fri til sportslige øvelser: "Næsten samtidig opdagede jeg ordet på en cigaretpakke. Mærket hed Militærsport (Wehrsport).” (Klemperer, 2010, S. 50)

Når han opfanger nye ord, vendinger eller symboler, skriver han det ned: “iagttag, studér, indprent, hvad der sker - for i morgen vil alt se anderledes ud, i morgen vil alt føles anderledes; fasthold, hvordan det manifesterer sig og fungerer lige nu.” (ibid, s. 23)

Men ser man på en anden af Hausers centrale pointer om den vernakulære retorik, peger de to forskere på to forskellige karakteristikker af det vernakulære. Hauser mener, at meningsdannelse først og fremmest skabes $i$ 
den vernakulære retorik. Det betyder, at meningsdannelse i befolkningen ikke bare er et produkt eller en konsekvens af en institutionel retorik, men af den retorik der foregår i befolkningen, og som ofte blot er igangsat af en institutionel retorik: "[R]hetorical dialogue reflects the collective reasoning process that public opinion expresses." [...] [T] he assent peculiar to public opinion is fashioned through the dialogue of vernacular talk." (Hauser, 1999, s. 85)

Hauser tager udgangspunkt i et moderne demokratisk samfund, hvor befolkningen har frihed til at ytre sig politisk. Derfor ser han det vernakulære som en retorisk praksis og handlemulighed (agency), som borgere kan benytte sig af for at skabe kollektiv meningsdannelse og udtrykke sym- og antipatier overfor magthaverne: "Nor is a shared ideology or even shared political interest a public's essential characteristic. Collective opinion is formed by the shared activity of communication”. (ibid, s. 97)

Hos Klemperer forholder det sig helt anderledes, idet han undersøger retoriske ytringer hos en befolkning, der grundet den politiske situation havde meget begrænsede retoriske handlemuligheder. Klemperers analyse viser af samme grund ikke tegn på en levende vernakulær diskurs, hvor befolkningen kollektivt skaber selvstændig meningsdannelse. Tværtimod peger analysen på en befolkning, der blot mimer magthavernes retorik. Som Klemperer skriver: “'Jeg vil hellere tro på sejren end blive hængt', lød en berlinsk vittighed ved krigens slutning”. (Klemperer 2010, 71) Men Hausers pointe kan måske samtidig pege på, at befolkningens mimen af den institutionelle retorik, virker som en forstærker for den retoriske effekt af nazismens retorik. For idet befolkningen tager det tredje riges sprog til sig og begynder at tale det, fungerer deres vernakulære retorik stadig som en kollektiv meningsdannelse, der accepterer nazismens agenda. Og det er derfor afgørende, at man undersøger befolkningens retorik. Som Hauser (1999) skriver: 
Publics may be repressed, distorted, or responsible, but any evaluation of their actual state requires that scholars and leaders engage in analyzes of the rhetorical ecology as well as the rhetorical acts. (s. 110)

\section{Deltagerobservation: Metodens styrker og udfordringer}

Klemperers metode kan betegnes som deltagerobservation, en metode med forbindelse til Chicago-skolen, socialantropologien og etnografien fra begyndelsen af forrige århundrede: "[E]n tradition, hvor man så at sige studerede og observerede sociale og kulturelle fænomener i egen baghave. Udgangspunktet var, at studier af egne og nære omgivelser både gav viden om og forståelse for disse” (Szulevicz, red. Svend Brinkmann \& Lene Tanggaard, 2015, s. 82)

Det er en kvalitativ metode, "hvor forskeren under sine observationer deltager i eller indgår i de forskellige praksisser, som observeres. [...] Generelt er deltagerobservation som metode velegnet til at beskrive og begribe det lokale, partikulære, situerede og sociale i menneskers hverdagsliv" (ibid, s. 83-85).

Indenfor den retoriske forskning har sådanne metoder, hvor forskeren undersøger en retorik, som den udfolder sig i felten, fået stor interesse de seneste år. I bogen text+field: Innovations in Rhetorical Method (2016) skriver Sara L. McKinnon et al:

In more recent years, a wider turn to the field has emerged in the work of prominent rhetoric, communication, and performance studies. [...] As these scholars demonstrate, cultural processes and meaning systems, dynamics of space/place, body knowledge, embodiment, and rhetorics of marginalized and excluded groups are often difficult to access through texts. They instead necessitate a prior first step - collection and documentation. (s. 3) 
Metoden giver den retoriske forsker mulighed for at undersøge retorisk handling, der ikke er forankret i en tekst eller database. En mulighed, der samtidig bidrager med et nyt syn på, hvad retorisk handling er: "Moving into the field may reward the critic with new perspectives on what constitutes rhetorical discource.” (ibid. s. 7)

Indvendinger mod metoden har bl.a. netop gået på, “at det er en meget tidskrævende tilgang, som de færreste forskere reelt har mulighed for at afsætte tilstrækkelig tid til [...].” (Szulevicz, red. Svend Brinkmann \& Lene Tanggaard, 2015, s. 88)

Klemperer fik, gennem tvang, tid til sin langvarige forskning. Og selvom Szulevicz (2015) påpeger, at mængden af tid ikke er garant for gode observationer (s. 89), så kræver observation af en længerevarende sproglig udvikling netop masser af tid. Klemperer levede sit liv, mens han observerede, han gjorde det til en integreret del af sin tilværelse og kunne derfor udføre undersøgelsen over mange år. Det er et aspekt, som Klemperers undersøgelse styrkes af: "Prolonged engagement with a community provides the critic with opportunities to explore broader characteristics of an context that enable or disable specific kinds of rhetorical practices.” (McKinnon et al., 2016, s. 10)

En anden indvending mod metoden er også, at der er en risiko for,

\footnotetext{
at forskeren overidentificerer sig så meget med det undersøgte felt, at valide tolkninger vanskeliggøres. [...] På den ene side er det at 'go native' en styrke, fordi deltagerobservatøren hermed også har fået et helt særligt kendskab til det observerede felt. På den anden kan det også repræsentere en fortolkningsbias, fordi man som forsker er blevet så optaget og personligt involveret i den lokale, observerede kontekst, at mere generelle og teoretiske tolkninger kan være vanskelige at foretage. (ibid, s. 90)
}

Det er en problematik, der i et vist omfang gør sig gældende for Klemperers studier. 
Forestillingen om den observerende forsker, som en neutral, objektiv og usynlig flue på væggen, er efterhånden blevet aflivet i moderne forskning. Den observerende er til stede og dermed selv en del af den verden og diskurs, der observeres: Deraf deltagerobservation, hvilket kalder på en selvbevidst refleksion over dobbeltrollen som observerende og medaktør i det observerede.

Klemperers rolle i undersøgelsen har flere forskellige aspekter. Han er selv jøde og er derfor særligt følelsesmæssigt involveret ift. nazisternes hetz mod den jødiske befolkning. Så selvom han måske mener, at han observerede objektivt: “Jeg så opmærksomt på og opmærksomt ind i mig selv. Jeg sagde til mig selv, at der jo også fandtes sådan noget som objektiv iagttagelse, og at jeg var skolet i dette” (Klemperer, 2010, s. 55), så observerede han (uundgåeligt) ud fra et had til nazisterne, som flere af de i artiklen anvendte citater også giver udtryk for. I artiklen "Articulating Rhetorical Field Methods: Challenges and Tensions" (2011) skriver Micheal K. Middleton et al. om denne udfordring for kritikeren i felten:

\footnotetext{
A central feature of the shift to in situ analysis is accounting for the relationship between text and critic, and especially the role of the critic's identity. Likewise, this question parallels critical rhetoricians' extant focus on the identity of the critic as a central plane of analysis in rhetorical criticism (s. 400)
}

Han observerede en befolkning, han selv var en del af. Men han hæver sig ikke over denne befolkning, som en bedrevidende borger, der bare peger på de andres ukritiske evne til at lade sig overtale. I stedet erkender han, at selv han, der brugte alt sin tid på at observere nazisternes sproglige indtog $\mathrm{i}$ befolkningens sprog, lod sig påvirke af den nazistiske retorik: "I temmelig lang tid har jeg skrevet i datid: det var ... det var. Men hvem var det, der i går sagde: 'Jeg må organisere lidt tobak?' Jeg er bange for, at det var mig selv.” (Klemperer, 2010, s. 125) Klemperer taler her om ordet organisere, der 
hænger sammen med nazisternes forestilling om organisation af arbejdet. Han uddyber senere:

[J]eg ved også, at ethvert dannet menneske har et lag i sin sjæl, som tilhører folket, og at al min kritiske opmærksomhed slet ikke hjælper, når det endelig gælder. På et eller andet tidspunkt overmandes jeg alligevel af den trykte løgn, når den trænger ind på mig fra alle sider, og betvivles af stadigt færre og til sidst af slet ingen. (ibid, s. 258)

Klemperers studie kan minde os om, at kritikeren i felten er en observator, der indsamler og konstruerer sin analysegenstand ud fra retoriske fragmenter, men er samtidig involveret i den retoriske udfoldelse som et subjekt, der selv indgår i den retoriske proces, der studeres. Og det er denne position, kritikeren har, som medskaber af den retoriske virkelighed, der giver kritikeren et dobbelt ansvar: "A critical rhetoric [and rhetorical field methods] asks the critic to take an interpretive position for the purpose of both understanding and political change.” (Middleton et al., 2011, s. 401)

Klemperer var bevidst om og reflekteret over, at han ikke var en neutral observatør, men var selv påvirket af den diskurs, han studerede. Men på trods af denne selvbevidsthed og evne til at gennemskue nazismens sproglige magt, tillagde han hverken, dem han studerede eller ham selv som kritiker, en retorisk handlekraft, der kunne skabe en forandring af den retoriske virkelighed. Som Aaron Hess skriver i artiklen "Critical-Rhetorical Ethnography: Rethinking the Place and Process of Rhetoric” (2011):

If critical rhetoric is to approach sites of vernacular discourse, a change in the notion of the critic is necessary toward one that attends to power as it is expressed and contested in spaces of advocacy. [...] Critical-rhetorical ethnographers would advocate for change by supporting the vernacular organization and its conception of a (new) political reality. (s. 134-135) 


\section{Klemperers publikumsopfattelse: En handlingslammet masse}

Klemperers manglende tro på sin egen og befolkningens retoriske handlekraft til at ændre den retoriske virkelighed kan måske have en del af sin årsag i den måde, Klemperer opfatter befolkningen og sig selv inkluderet som ét samlet subjekt, der handler og opfatter ensartet. På dette punkt, mener jeg, at den moderne retoriske tænkning kan bidrage til Klemperers værk.

Klemperer (2010) giver i bogen klart udtryk for en forståelse af befolkningen som en ensartet masse, der ikke evner kritisk at stille sig i mod nazisternes retorik, som alle fik "påtvunget gennem millioner af gentagelser, og som blev overtaget mekanisk og ubevidst." (s. 28) Modtagerne af den nazistiske retorik var, indikerer Klemperer, som samlet masse urefleksive, ukritiske og handlingslammede. Den nazistiske retorik var en gift, ingen kunne undslippe.

Jeg mener, der ligger et bemærkelsesværdigt sammenfald i den måde, Klemperer forstår og karakteriserer publikum med Hitlers publikumsopfattelse, som den kommer til udtryk i Mein Kampf og nazisternes generelle retorik. Og spørgsmålet er, om Klemperer netop blev påvirket i så høj grad af nazisternes publikumsforståelse og -behandling, at det havde en indvirkning på hans eget syn på befolkningen.

I Mein Kampf skriver Hitler (1925-1927/1999) om statslederen og befolkningen:

\footnotetext{
Ser man den ledende statsmands opgave $i$ at undfange den skabende tanke eller plan, ser man den ikke snarere i den kunst at få en tomhjernet făreflok til at forstå det geniale i hans planer og derved tigge sig til dens allernådigste bifald (s. 64).
}

Hitler (1925-1927/1999) skriver endvidere i kapitlet om propaganda: 


\begin{abstract}
Den store masses opfattelsesevne er så indskrænket, forståelsen ringe, glemsomheden til gengæld stor. Ud fra disse kendsgerninger bør al virkningsfuld propaganda indskrænke sig til meget få punkter og anvende disse som slagord så længe, indtil alle ved sådanne ord formår at forestille sig det tilsigtede. (s. 128)
\end{abstract}

Hitlers opfattelse og karakteristik af befolkningen er langt mere eksplicit i sin foragt end Klemperers. Og det betyder ikke, at Klemperer ikke selv opfattede det karakteristiske ved det nazistiske syn på befolkningen. Som han selv skriver: "En vigtig del af den nazistiske doktrins fundament var overbevisningen om massernes tankeløshed og absolutte fordummelse." (Klemperer, 2010, s. 252)

Men begge giver de på to forskellige måder et indtryk af modtagerne som dumme, passive og samlet i en masse. Dette sammenfald i synet på masserne kan dog ikke tilskrives nazisternes retorik alene, men bør også forstås i en bredere kulturhistorisk kontekst. Ideen om befolkningen som en masse og massemennesket er ikke en nazistisk opfindelse, men begreber der (atter) dukker op i tiden mellem første og anden verdenskrig. Den spanske filosof og kulturteoretiker José Ortega y Gasset peger i værket La rebelión de las masas (1929/1964) på, at fascismens fremmarch i Europa kan ses som en effekt af det moderne massemenneskes stigende indflydelse. Massemennesket opstår, mener Gasset, idet de lavere klasser i samfundet begynder at få de samme levestandarter og vilkår som de højere klasser. Flertallet i samfundet begynder at overtage mindretallets særlige position og indflydelse.

Det har selvfølgelig nogle store menneskelige fordele for samfundet. Men det er samtidig med til at skabe massemennesket, der for Gasset (1939/1964) er "enhver, der - på godt og ondt - ikke tillægger sig nogen særlig værdi, men føler sig som 'alle og enhver” (Gasset, 1964, s. 17). Det er "en mennesketype, der hverken ønsker at give begrundelser eller at have ret, men simpelthen er 
besluttet på at drive sine meninger igennem. Heri ligger det nye: i retten til ikke at have ret, ufornuftens fornuft." (ibid, s. 76)

Alt sammen karaktertræk, der giver fascismen og nazismen, gode vilkår for udbredelse.

Gasset peger altså på folket som noget forudeksisterende i samfundet, der konstitueres af en udvikling i samfundsstrukturen og en fælles mentalitet folket eksisterer som en objektiv størrelse. Ud fra en retorisk terminologi er det et kvalitativt publikumsbegreb, idet publikum er eksisterende uden for teksten og kan påvirkes med retorik. En opfattelse man også finder hos Bitzer, hvor publikum forstås som dem, der er i stand til at blive påvirkede af diskursen (mediators of change).

Masserne er ifl. Gasset (1939/1964)

\author{
ikke opstået af det rene ingenting. [...] De enkeltvæsener, der udgør \\ mængderne, eksisterede i forvejen, blot ikke som mængde. [...] Det er \\ indlysende indtil trivialitet, at en mængde normalt opstår, fordi ønsker, \\ idéer, væremåder falder sammen hos de enkelte individer. (s. 15-16)
}

Det er disse fælles ønsker, idéer og væremåder, som Hitler formår at udnytte retorisk. Men det gør han, fordi han til forskel fra Gasset forstår folket som noget mere eller noget andet end en allerede eksisterende samling individer med et objektivt og samfundsstrukturelt fælles eksistensgrundlag.

Flere retoriske forskere i nyere tid peger på, at folket ikke er en eksisterende størrelse forud for teksten, men er konstitueret af den. En retorisk retning, der senere fik betegnelsen konstitutiv retorik. I artiklen "In Search of 'The People’: A Rhetorical Alternative” (1975) skriver McGee:

'The people,' therefore, are not objectively real in the sense that they exist as a collective entity in nature; rather, they are fiction dreamed by an 
advocate and infused with and artificial, rhetorical reality by the agreement af an audience to participate in a collective fantasy. (s. 240)

Det forklarer McGee (1975)

by using as a context Hitler's description of the rhetorical process in which a leader transform individuals into a 'people' [...], an example of the sense in which 'people' exists in objective reality and as social fantasies at the same time. (s. 240-242)

I Mein Kampf udtrykker Hitler nemlig denne erkendelse af folkets dobbelte eksistensgrundlag og peger på, hvordan det kan udnyttes retorisk. McGee (1975) skriver:

In terms of objective reality, there are only individuals, who perhaps 'long for the same thing,' but who have no collective identity because they cannot describe 'what is before the inner eye,' the urge to achieve collective unity and collective goals. ${ }^{2}$ (s. 240)

McGee (1975) pointerer derfor, at folket kun "remain so long as the rhetoric which defined them has force, and in the end wilt away, becoming once again merely a collection of induviduals." (s. 242)

Erkendelsen af folkets dobbelte eksistensgrundlag kan på den ene side udnyttes retorisk som Hitler gjorde. Men på den anden side kan den også bruges til modkritik ved at pege på folket og masserne som en konstrueret illusion. Og det er i den sammenhæng interessant, om Klemperers undersøgelse giver dokumentation for fraværet af en sådan modkritik, eller om han som deltagende observatør simpelthen ikke for øje på den. Som Middleton et al. (2011) spørger: "how do critics remain accountable about

${ }^{2}$ McGee citerer her sproglige vendinger fra Hitlers Mein Kampf. 
which and in what manner marginal voices are made heard?” (s. 401) De enkelte mennesker Klemperer observerer er objektive størrelser. Men han ser dem snarere som en del af massen end som enkelte individer og kommer derfor ikke ud over illusionen om folket. Måske opfattede han derfor i højere grad end tilfældet var, at de enkelte individer handlede ensartet, mekanisk og ubevidst.

Erkendelsen af illusionen om folket er vigtig fordi, den giver et kritisk grundlag for at kunne opløse masserne til individer. Når Klemperer (2010) skriver: "jeg ved også, [...] at al min kritiske opmærksomhed slet ikke hjælper, når det endelig gælder. På et eller andet tidspunkt overmandes jeg alligevel af den trykte løgn”, (s. 258) så er det et udtryk for en manglende tro på individets selvstændige evne til kritisk at kunne afværge sprogets påvirkende kraft. En evne, der skal findes hos den enkelte - ikke i befolkningen som en samlet masse. Som den norske forfatter Karl Ove Knausgaard skriver i sit essay om Hitler i 6 bind af romanen Min kamp (2011, da. Min Kamp 2014):

\footnotetext{
Sprogets virkelighed er således en social virkelighed, det er jeg'ets, du'ets og vi'ets virkelighed. Men sprog er ikke en neutral størrelse der giver udtryk for noget allerede eksisterende, både jeg'et, du'et og vi'et farver og er farvet af sproget, som de skaber og bliver skabt i [...]. Det der gjorde ugerningerne i Det Tredje rige mulige, var en ekstrem forstærkning af vi'et, og den svækkelse af jeg'et det indebar, reducerede modstandskraften mod den gradvise umenneskeliggørelse. (Knausgaard 2014, 529)
}

Eller som Burke (1997) skriver om den nazistiske skabelse af folkelig enhed:

\footnotetext{
Længslen efter enhed og forening er ægte og respektgivende. Længslen efter national enhed - i verden som vi har den i dag - er ægte og respektgivende. Men enhed og forening, der opnås på basis af svindel, gennem emotionelle tricks der omdirigerer vores kritik fra dens egentlige mål, er ingen enhed overhoved. (s. 20)
}

J. Ovesen

$29 / 38$

Sakprosa.no 
Klemperer var uløseligt en del af sit eget genstandsfelt og et subjekt, hvis tanker og følelser havde indvirkning på hans observationer. Han var desuden en del af en tidsepoke, hvor ideen om massemennesket var udbredt, og hvor folket konstant blev retorisk konstrueret som ét samlet vi. Et vi, der skulle handle, tale og tænke ensartet. En sådan indvirkning er uundgåelig og kalder derfor på en selvbevidst refleksion fra observatørens side over dennes kritiske relation til genstandsfeltet.

Det er præcis her, at retorikfaget ikke kan undværes, idet det giver grundlag for kritisk dømmekraft. Som Hauser (1999) skriver om Aristoteles' Retorik:

\footnotetext{
Aristotle contends that the goal of rhetoric and the function of the audience are one and the same - krisis, or judgment. Krisis implies more than rational assent; it is the virtue of judgment informed by a disposition to act and feel in a particular way. The rationality of krisis entails the virtue of considering the phenomena of prudential conduct in terms that exceed one's personal interests and apply to every human. (s. 98)
}

Mens Klemperer forholder sig overvejende deskriptivt til sit genstandsfelt og peger på den retoriske situations håbløshed, tilbyder det antikke og moderne retorikfag en normativitet og evne til kritisk at stå imod sprogets magt.

Skal nazismens politiske succes forstås, vil det være nødvendigt at inddrage mange andre perspektiver end det retoriske. Materielle, samfundsmæssige, kulturelle og økonomiske forhold har alle været medvirkende faktorer for, at nazismen kunne vinde frem. Men fra det retoriske perspektiv er det værd at pege på, at et fravær af den kritisk retoriske bevidsthed og handlekraft har være en medvirkende faktor ift. til at skabe grobund for udbredelsen af fascistiske ideologier som nazismen. Simpelthen fordi bevidstheden om sprogets påvirkende kraft i højere grad var fraværende hos modtagerne. En kritisk bevidsthed, der ikke kan undværes, som Ono og Sloop (1995) skriver: 
Uncovering vernacular discourse is a worthwhile goal, but a more important goal is to construct a critical framework within which to discuss vernacular discourse; uncovering vernacular discourse is not, by itself, a liberatory practice. [...] we must move to a new level, that of critical suspicion, the kind of suspicion that rhetoricians have always given mainstream discourse. (s. 21)

\section{Klemperers værk i kontekst af den moderne retorikforskning}

Nazismen har i høj grad haft stor indflydelse på udviklingen af det moderne retorikfags historie. Den nye retoriske æra, der blev indledt efter anden verdenskrig med Burke og Perelman i spidsen, så retorikfaget og dets praktiske udfoldelse som en modbevægelse til det totalitære regime. Men selvom der er gået over 70 år siden krigens afslutning, er det bemærkelsesværdigt, at der ikke findes flere retoriske analyser af Hitlers og nazismens retorik. Den nye retorik tog teoretisk afsæt i nazismens retorik ved netop at adskille sig fra den. Måske af den grund har der ikke været retorisk interesse for at lave analyser af nazismens udnyttelse af sprogets magt. Men med denne kraftige adskillelse af retorik og manipulation får retorikfaget svært ved at forstå og forklare, både hvad der skete i 1930’ernes Tyskland, men også i andre mere nutidige retoriske begivenheder, hvor manipulation og retorik ikke lader sig adskille som to forskellige kategorier. Særligt i lyset af retorikforskningens fornyede interesse i effekt-begrebet, kan det være problematisk at opretholde en sådan separation.

Jeg mener, at studiet af den nazistiske retorik er yderst relevant for den moderne retorikforskning. For er vi ikke i stand til at undersøge og analysere den nazistiske retorik, vil der være mange andre retoriske tilfælde, hvor retorik og manipulation ikke lader sig adskille, og som derfor bliver problematiske at gå til med en retorisk tilgang. Klemperers værk viser en måde, hvorpå man retorisk kan studere dette overlap. 
Værket er desuden en kraftig påmindelse om, at Hitlers retoriske evner ikke skal negligeres. Christian Kock peger (i et manuskript under udgivelse) på, at teoretikere som Sebastian Haffner, forfatter til bogen The Meaning of Hitler (1978) fejlagtigt undervurderer Hitlers retoriske evner:

But can we believe that he won his command over multitudes in spite of, or with little help from, his rhetorical skill? Is it not more likely that intellectuals like Haffner, who were themselves impervious to the uncanny spell of Hitler's rhetoric, were also partly deaf to what might explain it? (Kock, u.å., s. 1)

En lignende pointe giver den italienske filosof Donatella Di Cesare fra et mere filosofisk perspektiv i bogen Heidegger og jøderne. De 'Sorte hæfter' (2015):

\footnotetext{
Som en halvt propagandistisk, halvt selvbiografisk tekst har Min Kamp længe været betragtet som en samling tomme banaliteter og galimatias. Det har forhindret et seriøst opgør med 'den forbudte bog' og bidraget til at gøre Hitler til personificeringen af det absolutte Onde, der som sådan ligger uden for fornuften og uden for historien. Hvis det var sådan, ville man imidlertid ikke kunne forstå hitlerismens stærke indflydelse på samtidens intellektuelle, jurister og filosoffer. (s. 84)
}

Fremtidige undersøgelser af nazismens retorik vil muligvis kunne belyse nogle vigtige aspekter, hvor nazismen og vores egen tid på et retorisk plan har noget tilfælles. Det kunne fx være en undersøgelse af, om eller på hvilken måde Donald Trumps retorik har nogle retoriske træk tilfælles med nazismens retorik. Meget tyder på, at Hitler og Trump, to demokratiskvalgte statsledere, har en retorisk tænkning tilfælles: Forsimplede budskaber, gentagelser, løgne, konstruering af en samlet fjende som årsag til divergerende samfundsproblemer, modstand mod det etablerede politiske system og tilbedelse af det nationalt særegne. Eller i en dansk kontekst som Henning Vangsgaard (2010) skriver i "Efterskrift" til Klemperers LTI: "Den nye diskurs om udlændinge, som man kan konstatere siden midten af 1990’erne, har med 
sine simplificerede typologier og fjendebilledskonstruktioner paralleller til den udvikling, LTI beskriver i 1930'ernes Tyskland.” (s. 383)

Uden indsigt i nazismens retoriske magt og tænkning, bliver det svært at forstå,hvorfor en sådan retorik vinder frem, og hvad dens påvirkningskraft består i.

Retorikforskningens reetablerede interesse i retorisk effekt, der som nævnt tidligere i artiklen fremstilles af Kiewe og Houck, bør derfor ikke lade sig begrænse, men i stedet sætte sig i stand til at undersøge enhver mekanisme, uagtet den etiske habitus, der har en påvirkende kraft overfor mennesket. Nazismen demonstrerede en retorik, der udviste enorm virkningskraft. Som Burke (1997) skriver om Hitlers Mein Kampf: "Denne bog er den nazistiske magis brønd; en rædselsvækkende magi, men en effektiv magi. Ethvert fornuftigt folk må ønske at studere en sådan magi.” (s. 9) Hvis retorikforskningen ikke formår at undersøge, hvad denne kraft eller magi består i, grundet en opdeling mellem retorik og manipulation med henvisning til det etiske aspekt af retorikfaget, misser vi en essentiel indsigt i retorisk effekt. En indsigt, vi ikke kan undvære i nutidens retoriske virkelighed. Som David A. Frank (2015) skriver: “The 'resurrection' of rhetoric's effects as a focus of study will help the field face the truly big questions confronting humanity." (s. 101)

Dette spørgsmål om, hvorfor og hvordan mennesket bliver påvirket af kommunikativ handlen, og hvordan sproget udøver magt over os, er en opgave for den retoriske forskning at besvare. For det er den indsigt, der skal værne os mod, at vi ikke reduceres til den tomhjernede färeflok, Hitler skriver om. 


\section{Litteratur}

Aristoteles. (2007). Retorik. Museum Tusculanums Forlag. København Burke, Kenneth. (1997). "Retorikken i Hitlers 'Min Kamp”. Rhetorica Scandinavica, Nr. 4. Udgivet 1939 med titlen: “The Rhetoric of Hitler's 'Battle"'.

Brinkmann, Svend. (2013). Kvalitativ udforskning af hverdagslivet. Hans Reitzel. København.

Cecare, Donatella Di. (2015). Heidegger og jøderne, De 'Sorte hæfter'. Forlaget Vandkunsten. København. Udgivet 2014 med titlen: Heidegger a gli ebri. I 'Quaderni neri'.

Frank, David A. (red. Amos Kiewe \& Davis W. Houck). (2015). The effect of rhetoric and the rhetoric of effects, past, present, future. "Rhetoric's Effects, the Vita Activa, and the Rhetorical Turn in Twentieth-Century Thought". The University of South Carolina Press. Columbia.

Gasset, José Ortega Y. (1964). Massernes Oprør. Gyldendal. København. Udgivet 1931 med titlen: La Rebelión de las Masas.

Hauser, Gerard A. (1999). Vernacular voices, the rhetoric of publics and public spheres. University of South Carolina Press. Columbia, S.C.

Hess, Aaron. (2011). "Critical-Rhetorical Ethnography: Rethinking the Place and Process of Rhetoric”. Communication Studies, vol. 62

Hitler, Adolf. (1999). Min Kamp. Jørgen Paludans Forlag. 8 oplag. Udgivet 1925-1927 med titlen: Mein Kampf.

Howard, Robert Glenn. (2010). Public Modalities. Rhetoric, Culture, Media J. Ovesen 
and the Shape of Public Life. The University of Alabama Press. Tuscaloosa, Alabama.

Kiewe, Amos \& Davis W. Houck. (2015). The effect of rhetoric and the rhetoric of effects, past, present, future. The University of South Carolina Press. Columbia.

Kjeldsen, Jens E. (2008). “Retoriske omstændigheder. Retorikken i en fragmenteret, foranderlig og kompleks verden”. Rhetorica Scandinavica, vol. 48.

Kjeldsen, Jens E. (2015). “Det virkelige retoriske publikum”. Retorik och lärande. Kunskap - Bildning - Ansvar. Nordiska konferensen för retorikforskning (NKRF) 2014. Lunds Universitet.

Klemperer, Victor. (2010). LTI - Lingua Tertii Emperii, Det Tredje Riges Sprog, en filologs notesbog. Tekst og Tale Forlag. København. Udgivet 1947 med titlen: Notizbuch eines Philologen.

Knausgård, Karl Ove. (2014). Min kamp 6 (2 udgave, 2 oplag). Lindhardt og Ringhof Forlag. København.

Kock, Christian. (u.å.). "Hitler's Evil Oratory-Illuminated by Rhetoricians of Late Antiquity". Under udgivelse. i.s.

McGee, Michael C. (1975). "In Search of 'The People': A Rhetorical Alternative". The Quarterly Journal of Speech, vol. 61.

McGee, Michael C. (1990). “Text, Context, and the Fragmentation of Contemporary Culture”. Western Journal of Speech Communication, vol. 54. 
McKinnon, Sara L. et al. (2016). Text+field: Innovations in Rhetorical Method. The Pennsylvania State University Press. University Park, Pennsylvania.

Middleton, Michael K. et al. (2011). “Articulating Rhetorical Field Methods: Challenges and Tensions”. Westen Journal of Communication, vol 75.

Ono, Kent A. \& John M. Sloop. (1995). “The Critique of Vernacular Discourse”. Communication Monographs, vol. 62.

Roer, Hanne. (2005). Retorikkens Rige - retorik og argumentation.

"Forord”. Hans Reitzel. København.

Szulevicz, Thomas. (red. Svend Brinkmann \& Lene Tanggaard). (2015). Kvalitative metoder: En grundbog. Kap. 3: "Deltagerobservation”. Hans Reitzel. København.

Vangsgaard, Henning. (2010). LTI - Lingua Tertii Emperii, Det Tredje Riges Sprog, en filologs notesbog. "Efterskrift”. Tekst og Tale Forlag. København. 